\title{
Article \\ Stretchable Transparent Light-Emitting Diodes Based on InGaN/GaN Quantum Well Microwires and Carbon Nanotube Films
}

\author{
Fedor M. Kochetkov ${ }^{1, *}$, Vladimir Neplokh ${ }^{1,2}{ }^{\mathbb{D}}$, Viktoria A. Mastalieva ${ }^{1}$, Sungat Mukhangali ${ }^{1}$, Aleksandr \\ A. Vorob'ev ${ }^{1}{ }^{\mathbb{D}}$, Aleksandr V. Uvarov ${ }^{1}$, Filipp E. Komissarenko ${ }^{3} \mathbb{D}$, Dmitry M. Mitin ${ }^{1,2} \mathbb{D}^{\mathbb{D}}$, Akanksha Kapoor ${ }^{4}$,

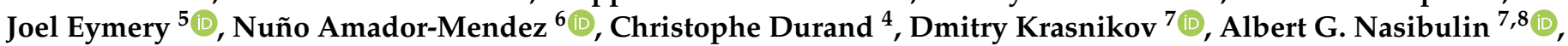 \\ Maria Tchernycheva ${ }^{6}$ and Ivan S. Mukhin ${ }^{1,3}$
}

check for updates

Citation: Kochetkov, F.M.; Neplokh, V.; Mastalieva, V.A.; Mukhangali, S.; Vorob'ev, A.A.; Uvarov, A.V.; Komissarenko, F.E.; Mitin, D.M.; Kapoor, A.; Eymery, J.; et al. Stretchable Transparent Light-Emitting Diodes Based on InGaN/GaN Quantum Well Microwires and Carbon Nanotube Films. Nanomaterials 2021, 11, 1503. https://doi.org/10.3390/ nano11061503

Academic Editor: Jong-Soo Lee

Received: 22 April 2021

Accepted: 1 June 2021

Published: 7 June 2021

Publisher's Note: MDPI stays neutral with regard to jurisdictional claims in published maps and institutional affiliations.

Copyright: (c) 2021 by the authors. Licensee MDPI, Basel, Switzerland. This article is an open access article distributed under the terms and conditions of the Creative Commons Attribution (CC BY) license (https:// creativecommons.org/licenses/by/ $4.0 /)$.
1 Department of Physics, Alferov University, Khlopina 8/3, 194021 St. Petersburg, Russia; vneplox@gmail.com (V.N.); strindberg76@mail.ru (V.A.M.); sungat15004@gmail.com (S.M.); alex.spbau@mail.ru (A.A.V.); lumenlight@mail.ru (A.V.U.); mitindm@mail.ru (D.M.M.); imukhin@spbau.ru (I.S.M.)

2 Institute of Machine Engineering, Materials and Transport, Peter the Great St. Petersburg Polytechnic University, Polytechnicheskaya 29, 195251 St. Petersburg, Russia

3 Department of Physics and Engineering, ITMO University, Lomonosova 9, 197101 St. Petersburg, Russia; filipp.komissarenko@metalab.ifmo.ru

4 Nanophysics and Semiconductors Laboratory, University Grenoble Alpes, PHELIQS, IRIG, CEA, 38000 Grenoble, France; aku.kapoor19@gmail.com (A.K.); christophe.durand@cea.fr (C.D.)

5 Nanostructures and Synchrotron Radiation Laboratory University Grenoble Alpes, MEM, IRIG, CEA, 38000 Grenoble, France; aku.kapoor19@gmail.com (A.K.); joel.eymery@cea.fr

6 Centre of Nanosciences and Nanotechnologies, UMR 9001 CNRS, University Paris-Saclay, 10 Boulevard Thomas Gobert, 91120 Palaiseau, France; nuno.amador@c2n.upsaclay.fr (N.A.-M.); maria.tchernycheva@u-psud.fr (M.T.)

7 Skolkovo Institute of Science and Technology, Bolshoy Boulevard 30/1, 121205 Moscow, Russia; d.krasnikov@skoltech.ru (D.K.); a.nasibulin@skoltech.ru (A.G.N.)

8 School of Chemical Engineering, Aalto University, P.O. Box 16100, FI-00076 Espoo, Finland

* Correspondence: kochetkovfm@spbau.ru

Abstract: We propose and demonstrate both flexible and stretchable blue light-emitting diodes based on core/shell InGaN/GaN quantum well microwires embedded in polydimethylsiloxane membranes with strain-insensitive transparent electrodes involving single-walled carbon nanotubes. InGaN/GaN core-shell microwires were grown by metal-organic vapor phase epitaxy, encapsulated into a polydimethylsiloxane film, and then released from the growth substrate. The fabricated free-standing membrane of light-emitting diodes with contacts of single-walled carbon nanotube films can stand up to $20 \%$ stretching while maintaining efficient operation. Membrane-based LEDs show less than $15 \%$ degradation of electroluminescence intensity after 20 cycles of stretching thus opening an avenue for highly deformable inorganic devices.

Keywords: stretchable LED; InGaN; nanowires; single-walled carbon nanotubes; MOVPE

\section{Introduction}

Stretchable and flexible optoelectronic structures are the envisioned base for the next generation of smart wearable devices with enhanced functionality and usability [1-9]. Stretchable optoelectronics is a focus of research for many companies specializing in numerical billboards and displays as a final phase of the evolution of flexible displays. The major advantage is their form-factor adapting for various applications, such as foldable screens [10,11], bio-integrated devices [12-16], and wearable sensors [17-19]. Nowadays, the most developed and commercially successful flexible device technology is based on organic materials $[20,21]$. The main advantage of the organic light-emitting diodes (OLED) is a relatively inexpensive and scalable fabrication coupled with a certain electroluminescence 
(EL) efficiency. However, organic devices are inferior to inorganic semiconductor emitters in terms of long-term stability, luminance, and external quantum efficiency, especially in the blue and red spectral ranges.

Semiconductor microwires (MWs) have been investigated during the last five years as promising candidates for flexible light emitting diodes [6,22]. Owing to their small footprint, MWs can be bent without structural damage associated with the blue, green, and white emission [23,24]. Thus, integrated polymer/MW membrane withstands stretching and bending with only a negligible deformation of the MWs, thereby preserving the active material integrity. Therefore, a composite polymer/MW membrane can withstand high stretching thanks to the polymer elasticity. Among the earliest demonstrations of polymer/MW (or nanowire) LEDs were ZnO nanowire LEDs [25].

In addition to the stretchable emissive layer, the stretchable LEDs require proper transparent electric contacts. So far, the best stretchable performance in OLED devices was demonstrated with contacts based on four-layer graphene with $80 \%$ optical transparency and $\sim 70 \mathrm{Ohm} /$ square sheet resistance [26]. There are also reports describing stretchable OLED devices [27] with $\mathrm{Ag}(80 \mathrm{~nm}) / \mathrm{MoO}_{3}(3 \mathrm{~nm})$ as anode and $\mathrm{Ca}(3 \mathrm{~nm}) / \mathrm{Ag}(18 \mathrm{~nm})$ as cathode contacts deposited on photopolymer. The main benefits of this structure are stretchability and flexibility, although the photopolymer surface becomes crumpled after stretching, diminishing device transparency.

Meanwhile, single-walled carbon nanotube (SWCNT) contacts synthesized by chemical vapor deposition have $\sim 20 \mathrm{Ohm}$ per square at $80 \%$ transmittance [28] thus providing the best conductivity, transparency, and stretchability compromise. SWCNT contacts on polydimethylsiloxane (PDMS) films preserve the device form due to elastic deformation of the whole structure [29] as the SWCNT films are applied to a pre-stretched PDMS film. A comparison given in [30] of graphene multilayers and CNT stretchable electrodes showed that CNTs are affected less by the deformation than the graphene multilayers (namely, they differ by 1.44 times in terms of conductivity degradation).

In the present study, we combine the two building blocks, both having good flexibility and stretchability, namely the polymer/microwire (PDMS/MW) composite membranes and the transparent SWCNT-based contacts, to demonstrate transparent inorganic stretchable LED. The LEDs are based on InGaN/GaN core-shell microwires producing blue electroluminescence, while the SWCNT films serve as an efficient transparent electrode insensitive to stretching. We show that the electroluminescence spectral shape and intensity are almost insensitive to the stretching conditions for deformations up to $20 \%$. The introduced methods open the route towards stretchable display development based on inorganic light-emitting materials.

\section{Materials and Methods}

\subsection{Synthesis of In $G a N / G a N$ Microwire Arrays}

The GaN MWs with core-shell InGaN/GaN multiple quantum wells (MQWs) were grown by metal-organic vapor phase epitaxy (MOVPE) on sapphire substrates [31,32]. In the first stage, n-doped GaN MWs were grown based on high silane flux that passivates the sidewall surfaces by the spontaneous formation of $\mathrm{SiN}_{\mathrm{x}}$ ultrathin layer [33]. The GaN MWs are highly n-doped (estimated as $\sim 10^{20} \mathrm{~cm}^{-3}$ [34]) with a typical length of $10 \mu \mathrm{m}$ and a diameter in the range of $0.7-1.5 \mu \mathrm{m}$. In the second stage, another non-intentionally doped GaN segment of about $7 \mu \mathrm{m}$ length was grown without silane flux leading to a reduced doping concentration (about $10^{18} \mathrm{~cm}^{-3}$ [35]). The active MQW region was deposited directly on the MW sidewall surface by switching from axial to radial growth thanks to the reduction of the growth temperature from $1040{ }^{\circ} \mathrm{C}$ to $750{ }^{\circ} \mathrm{C}$. Due to the presence of the $\mathrm{SiN}_{\mathrm{x}}$ layer around the wire base, the radial growth is inhibited in the lower wire part and the core/shell heterostructure is only formed around the upper non-intentionally doped wire part, as described in [36,37]. The active region consisted of seven periods of 5-nm InGaN quantum wells delimited by $10-\mathrm{nm}$-thick $\mathrm{GaN}$ barriers and with an indium content of $15 \%$. The growth was pursued with the deposition of the $\mathrm{p}-\mathrm{GaN} 100 \mathrm{~nm}$-thick shell, the 
hole concentration is estimated to be in the $10^{16}-10^{17} \mathrm{~cm}^{-3}$ range [38]. The MW density is about $5 \times 10^{6}$ per $\mathrm{cm}^{2}$. The MW morphology and the internal structure are illustrated in Figure $1 \mathrm{a}-\mathrm{c}$.

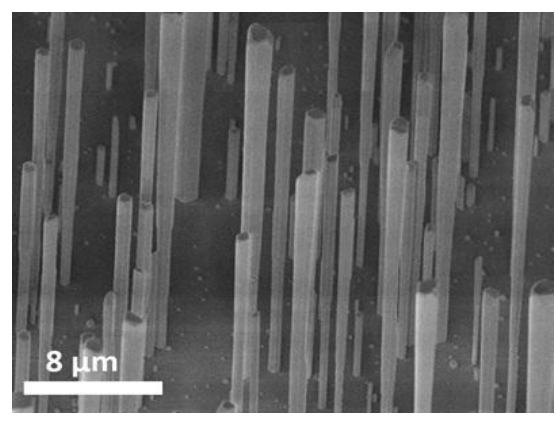

(a)

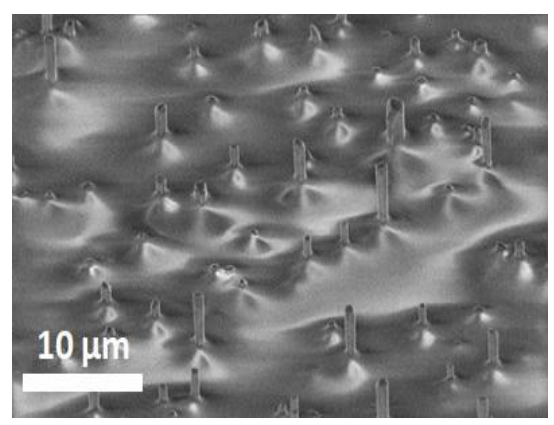

(b)

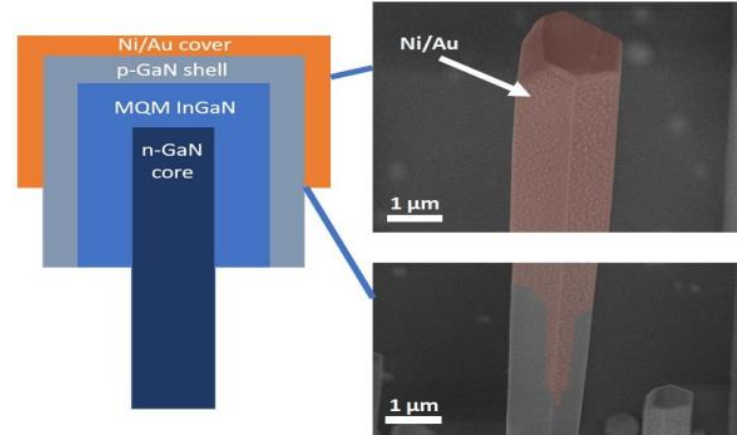

(c)

Figure 1. Forty-five-degree tilted SEM images of (a) an as-grown MW array, and (b) InGaN/GaN microwires encapsulated into PDMS. (c) Schematic of InGaN/GaN MQW MW structure with SEM images of a MW tip and the border of an area metalized with Ni/Au (artificial red color denotes metal). The metal layer did not contact MW cores.

The previously published cathodoluminescence (CL) mapping of the InGaN/GaN MWs synthesized under similar growth conditions $[39,40]$ showed that this type of wires is characterized by the main blue emission arising from the radial QWs and an additional long-wavelength emission, which can be associated with a defect band.

\subsection{PDMS/MW Membrane Fabrication}

In this work, the transparent, flexible, and stretchable contacts to MWs were based on SWCNT films. In order to provide an ohmic contact between the SWCNT film and the MW array, $5 \mathrm{~nm}$ thick metal layers of $\mathrm{Ni} / \mathrm{Au}$ were deposited on $\mathrm{MW}$ top parts by an e-gun evaporator. Metallization of MW topmost parts was carried out at a $78^{\circ}$ deposition angle in relation to the MW axis that allows avoiding undesirable metal deposition on the lower parts of MWs due to the shadowing effect (Figure 1c). After deposition, metalized MWs were annealed in the ambient atmosphere at $500{ }^{\circ} \mathrm{C}$ for $10 \mathrm{~min}$ to form an ohmic contact to the p-GaN shell [41].

Then, the MW array with pre-deposited thin metal layers was encapsulated into a PDMS layer by G-coating method $[42,43]$. G-coating is performed with a swinging-bucket centrifuge instead of a standard spinner. To process the samples, we used a high-speed centrifuge Eppendorf 5804.

For the polymer membrane formation, a commercial PDMS (Dow Corning Sylgard 184) was mixed in a base to a curing agent ratio of 10 to 1 . The mixture was dropped onto 3 square $\mathrm{cm}$ size samples and G-coated at $5000 \mathrm{rpm}$ for $15 \mathrm{~min}$ until the sample surface became matt due to the light scattering by revealed MW heads (Figure 1b). 
After PDMS deposition, the samples were baked in a muffle oven at $80{ }^{\circ} \mathrm{C}$ for $12 \mathrm{~h}$ followed by etching in $\mathrm{O}_{2}$ plasma to remove the residual PDMS wetting layer from MW top parts for further contact application. The procedure was previously reported in [42] and [43]. Then, the PDMS/MW membranes were released from the growth substrate by a razor blade [42].

\subsection{Synthesis and Application of SWCNT Contacts}

SWCNTs were synthesized by the aerosol chemical vapor deposition (CVD) method described elsewhere $[44,45]$. SWCNTs were collected directly at the outlet of the reactor by a nitrocellulose filter. SWCNT films used in the present work were of $80 \%$ transparency at $550 \mathrm{~nm}$ wavelength, while the sheet resistance can reach $20 \mathrm{Ohm} /$ square [28,46].

SWCNT contact pads were applied to free-standing PDMS/MW membranes. In order to fabricate strain-insensitive contacts, SWCNT pads were applied onto pre-stretched PDMS samples: when released at initial non-stretched state nanotube film compresses to form wrinkles and returns to an initial state when stretched [29]. In comparison, SWCNT films applied to non-stretched PDMS demonstrate a significant conductivity degradation after stretching as it was shown in [29] and reproduced in our work further.

It should be noted that the SWCNT films serve as electrical contacts (i.e., transparent electrodes) and are not directly involved in the radiative process occurring in InGaN/GaN MQWs in MWs. Therefore, we consider the SWCNT film wrinkle cavity effect [47] on stretchable LED performance to be negligible. Indeed, in the case of stretchable LED geometry, the light emission is extracted at MW top parts protruding the SWCNT film layer, so the light interaction with SWCNTs is expected to be insignificant due to the film transparency.

As prepared SWCNT films on a nitrocellulose filter were cut to an appropriate size of approximately $0.3 \mathrm{~mm}^{2}$, then the contact pads were applied onto both sides of $20 \%$ mechanically pre-stretched PDMS/MW membrane and wetted by isopropyl alcohol (IPA) droplets in order to provide an effective adhesion of the SWCNT pads to the PDMS surface. After IPA evaporation, the nitrocellulose filters were easily removed with a soft air flow. In the end, membrane was relaxed and SWCNT contact pads provided a safety margin for subsequent stretches as a stable electrode [29]. The value of $20 \%$ mechanical stretch was chosen because of the following reasons: (a) thin PDMS membranes have a high risk of tearing at stretching higher than $30 \%$ and (b) $20 \%$ is a good compromise between a high transparency and deformability of stretchable SWCNTs (the more a PDMS film is pre-stretched, the less SWCNT film is transparent at normal states due to the wrinkles).

For convenience of electrical measurement, $0.1 \mathrm{~mm}$ thin copper wires were applied to SWCNT contact pads with silver lacquer droplets. Then, the whole structure was buried into PDMS except copper wire tails and baked in an oven for $4 \mathrm{~h}$ at $80^{\circ} \mathrm{C}$ (the workflow is shown in Figure 2).

\subsection{Optical and Electrical Characterization}

Optical transparency of the produced stretchable LED was measured with an integrating sphere. The stretchable LEDs were stuck to glass, which also served as a reference. Argon lamp light was focused on a contacted area of PDMS/MW membrane placed after the integrating sphere slits.

We verified electrical stability of stretchable SWCNT contacts similarly to [29]. The SWCNT stripes were applied to relaxed as well as to pre-stretched by $10 \%$ PDMS films (Figure S1). The SWCNT stripes were connected with copper wires and silver lacquer, and then buried into PDMS the same way as the LED device (Figure 2). I-V measurements for reference SWCNT stripes, and for stretchable LED were performed with a Keithley 2400 sourcemeter, and stretching was controlled with a vernier caliper with an accuracy of $0.05 \mathrm{~mm}$. For the stretching test of LED devices, the operating current was fixed, and the device performance was controlled by voltage measurements. EL spectra were measured with an Avantes AvaSpec ULS2048XL spectrometer (Avantes Inc., Louisville, CO, USA). 


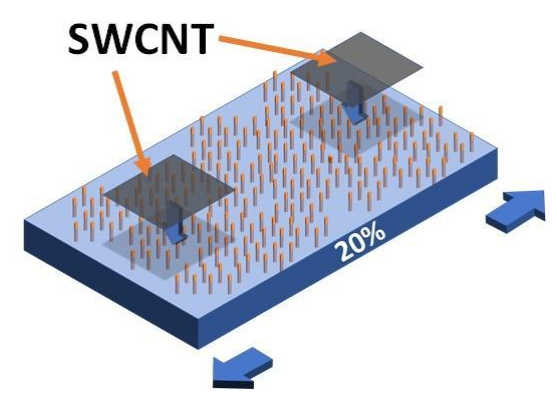

(a)

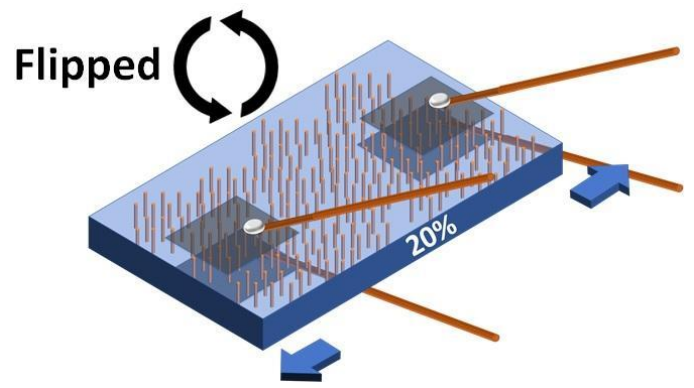

(c)

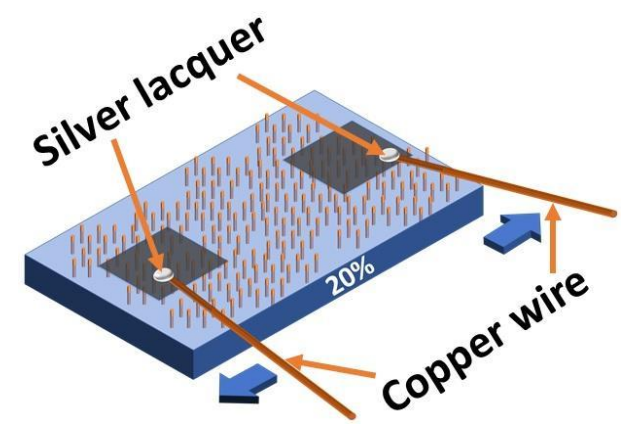

(b)

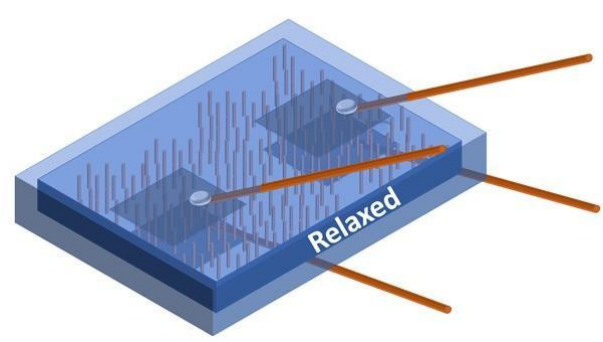

(d)

Figure 2. Workflow of electrical contacting to a PDMS/MW membrane: (a) application of SWCNT contact pads onto the upper side of $20 \%$ pre-stretched PDMS/MW membrane, (b) connection to the SWCNT contact pads with copper wires and silver lacquer, (c) application of electrical contact to the bottom side of PDMS/MW membrane, (d) relaxed LED device buried into PDMS.

\section{Results and Discussion}

\subsection{Device Transparency Measurements}

The integral transparency of the stretchable LEDs was estimated as 0.43 compared to the reference Figure 3 . This value can be explained by absorption in the two contact layers of stretched by $20 \%$ SWCNT $((0.8 / 1.2) \times(0.8 / 1.2)=0.44)$ and in the PDMS/MW membrane (responsible for the remnant $1 \%$ decrease). It should be noted that the transmission loss is spectrally flat.

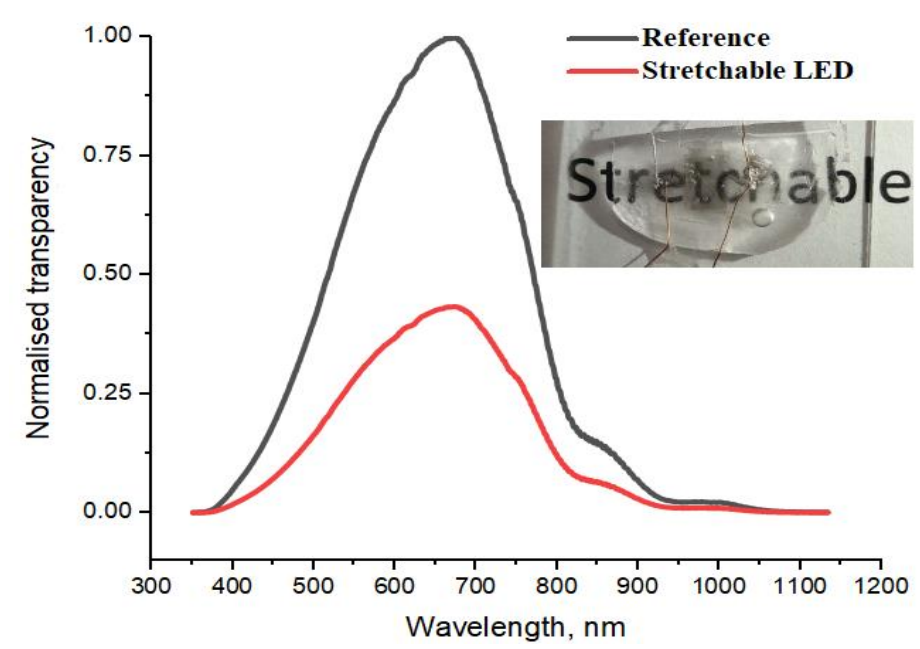

Figure 3. Stretchable LED spectral transparency (red line) normalized to the peak value of a reference glass substrate (black line). Inset shows a photo of the LED device on reference glass substrate put on a paper with a printed word. 


\subsection{Electrical Characterization}

The results of conductivity measurements of the test SWCNT stripes on blank PDMS films demonstrated significantly different rates of degradation depending on the prestretching. Specifically, the initially unstretched samples showed $40 \%$ of conductivity reduction, while the pre-stretched samples were characterized by only $5 \%$ conductivity decrease at 10\% stretch (Figure S2). Other pre-stretched rates were thoroughly studied in [29].

In order to prove that the stretchable LEDs keep their electrical properties during stretching, the I-V curves were measured for the as-processed samples, and during stretching cycles and after releasing the strain. The measured I-V curves for a representative device stretched by $20 \%$ are presented in Figure 4 . A significant current reduction was observed for the first stretching: the current for the relaxed LED is $0.25 \mathrm{~mA}$, while for the stretched LED the value dropped to $0.2 \mathrm{~mA}$ at the same voltage of $8 \mathrm{~V}$ (a rough estimation of the current density derived from this value gives $10 \mathrm{~A} / \mathrm{cm}^{2}$, which correlates with the results reported in the literature for thin film InGaN LEDs $[48,49])$. However, for the subsequent stretching cycles, no further current loss was observed. The knee voltage did not change due to the stretching, indicating a stable SWCNT/MW contact interface. We speculate that the significant decrease of the current at the first stretching can be explained by an impairment of the weakest SWCNT/MW contacts, while the majority of the MWs remained contacted after the initial and consequent stretching. One might suspect that the rigid silver lacquer droplets may introduce local mechanical instability of the contacts at stretching. However, the reference SWCNT contacts did not demonstrate any damages due to the silver lacquer droplets (Figure S1), therefore we conclude that small silver lacquer droplets did not significantly hamper the device stretchability.

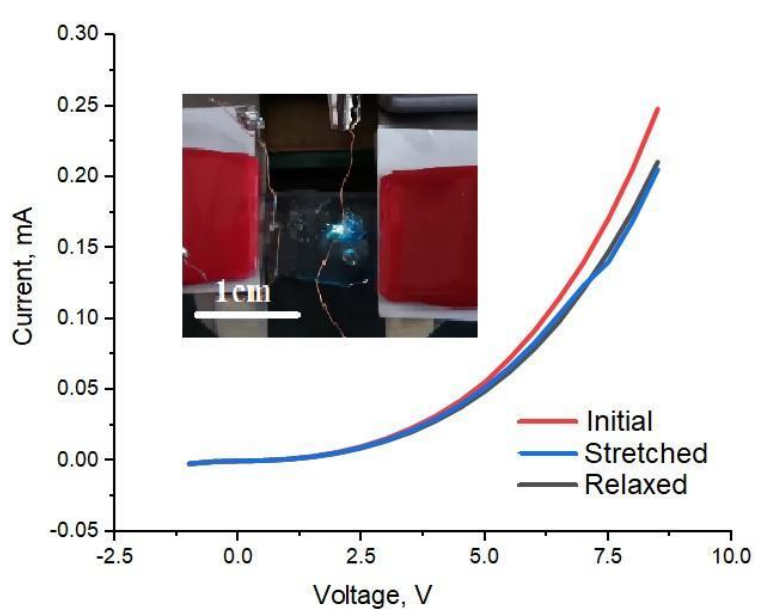

(a)

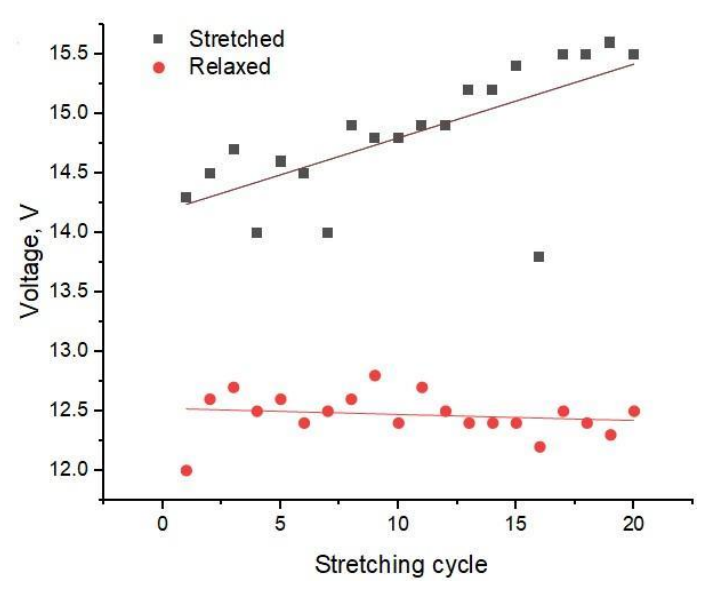

(b)

Figure 4. (a) I-V curves of a representative stretchable LED in initial (red line), stretched by $20 \%$ for the first time (blue line), and released (black line) states. (b) Working voltage during the stretching test of the LED for a constant injection current. Inset in (a) demonstrates a photo of the functioning stretchable LED device.

Stretching tests confirmed electrical contact stability and the emissive membrane integrity for 20 cycles of stretching (by 10\%) and releasing (Figure 4). The voltage was measured for each iteration at a constant LED injection current value of $0.4 \mathrm{~mA}$. The value of stretching was controlled by a vernier caliper with an accuracy of $0.05 \mathrm{~mm}$ (i.e., $2.5 \%$ of the applied stretching). PDMS/MW membranes showed 15\% resistivity increase (deduced from the measured voltage) after 20 cycles under stretched conditions, while in the relaxed state stretchable LED retained the initial value of resistivity. We associate the increase in resistivity with a micro damage of the SWCNT films, which is insignificant at the relaxed state due to wrinkles formation but leads to SWCNT network integrity impairment in 
the stretched state, when the wrinkles are released, or could be attributed to the baseline stabilization effect observed in a few dozen of the first film stretching cycles (training) [29].

\subsection{Electroluminescence Measurements}

Optoelectronic properties of InGaN/GaN MW arrays, including MW/PDMS membrane configuration, were investigated in detail in our previously reported works including $[23,24,31,38,49]$, etc. Flexibility of InGaN/GaN MW/PDMS membrane LEDs and SWCNT films were also thoroughly studied in $[23,24,28,41,42]$, so it is not addressed in the presented work. Therefore, in this section we focus on stretchability-related properties of the fabricated stretchable LEDs.

EL spectra of a representative stretchable LED were measured at $10 \mathrm{~V}, 11 \mathrm{~V}$, and $12 \mathrm{~V}$ bias applied in the relaxed and $20 \%$ stretched states. The relatively high functioning voltage is a typical problem of MW / PDMS LEDs explained by parasitic electric barriers and high series resistance discussed elsewhere $[23,24]$. As shown in Figure 5, the blue line at 450-460 nm, which originates from MQWs, dominated over the defect yellow band centered at $560 \mathrm{~nm}$ [39]. The EL spectra obtained at different biases are vertically shifted for clarity in Figure 5. As the applied voltage increased in the EL experiment, almost no blueshift was observed, which is indeed expected for m-plane QWs [31], which contrary to c-plane QWs do not exhibit polarization internal field screening [50,51]. Under stretching, the EL signal from the contacted area remained homogeneous, indicating stability of MW contacting proven by the preserved blue line intensity.

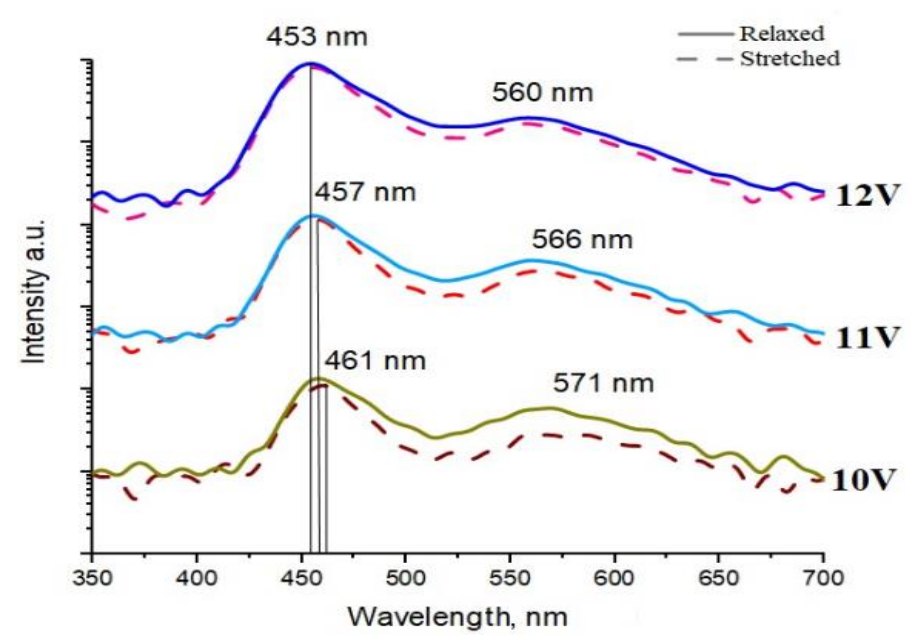

Figure 5. EL spectra of a representative LED in relaxed (solid line) and stretched (dashed line) states obtained under different applied voltages. The EL spectra are vertically shifted for clarity.

It should be stressed that stretching did not have any significant effect on the peak positions and spectrum shapes, indicating a high stability of functioning stretchable LEDs. Interestingly, the yellow band became less intense under stretching, especially at lower voltages. This effect will be studied elsewhere.

\section{Conclusions}

In conclusion, we developed and demonstrated stretchable LEDs based on integration of vertical nitride microwire arrays embedded in a PDMS membrane and transparent strain-insensitive SWCNT electrodes. We show repeatable stretching with a minor decrease of the EL signal: less than 15\% after 20 cycles. The method for application of SWCNT pads onto a pre-stretch PDMS/MW membrane provides stable stretchable electrical contact. This technology opens new routes for efficient stretchable LED displays and other optoelectronic devices based on inorganic light-emitting materials. 
Supplementary Materials: The following are available online at https: / www.mdpi.com/article/ 10.3390/nano11061503/s1, Figure S1: Schematic image of electrical contacting to a PDMS film; Figure S2: Representative voltage at constant current for a not pre-stretched SWCNT sample and a pre-stretched.

Author Contributions: Conceptualization, F.M.K., V.N., V.A.M., S.M., J.E., N.A.-M., D.K., A.G.N., M.T. and I.S.M.; methodology, V.N., D.K., A.G.N. and I.S.M.; validation, V.N. and C.D.; investigation, F.M.K., V.N., V.A.M., S.M., A.A.V., A.V.U., N.A.-M., C.D., M.T. and I.S.M.; resources, A.G.N.; data curation, F.M.K., V.N., C.D., A.G.N., M.T. and I.S.M.; writing-original draft preparation, F.M.K.; writing-review and editing, F.M.K., V.N., S.M., C.D., D.K., M.T. and I.S.M.; visualization, F.M.K., V.A.M. and S.M.; supervision, V.N., D.M.M., A.G.N., M.T. and I.S.M.; project administration, V.N., M.T. and I.S.M.; funding acquisition, V.N., F.E.K., A.K., J.E., A.G.N., M.T. and I.S.M. All authors have read and agreed to the published version of the manuscript.

Funding: J.E., C.D. and A.K. thank French National Labex GaNeX (ANR-11-LABX-0014) for MW synthesis and CL measurements. V.N. thanks the Russian Foundation for Basic Research (RFBR project no. 19-32-60040) for PDMS/MW membrane fabrication and optical measurements. I.S.M., V.N., F.M.K. thank the support from the Russian Science Foundation (grant 20-19-00256) for PDMS synthesis and electrical measurements. D.K. and A.G.N. thank Russian Foundation of Basic Research project no. 20-03-00804 for the synthesis of carbon nanotubes. F.E.K. thanks the support from the Russian Science Foundation (grant 19-79-00313) for the LED array encapsulation and membrane transfer. I.S.M., F.M.K., V.N., V.A.M., S.M., A.A.V., A.V.U., and D.A.M. thank the Ministry of Science and Higher Education of the Russian Federation (FSRM-2020-0005) for the general support. N.A. and M.T. acknowledge the financial support from the ITN Marie Curie project INDEED (grant no. 722176), by the Indo-French Centre for the Promotion of Advanced Research (IFCPAR/CEFIPRA project no. 6008-1) for MW/PDMS membrane processing and characterization.

Data Availability Statement: The data presented in this study are available on request from the corresponding author. The data are not publicly available due to the author's readiness to provide it on request.

Acknowledgments: The authors J.E., C.D. and A.K. would like to thank Jean Dussaud for his work on the MOVPE setup. V.N. would like to thank Maria Baeva for her assistance with the stretchable LED transparency measurements.

Conflicts of Interest: The authors declare no conflict of interest.

\section{References}

1. Su, Y.; Ping, X.; Yu, K.J.; Lee, J.W.; Fan, J.A.; Wang, B.; Li, M.; Li, R.; Harburg, D.V.; Huang, Y.; et al. In-Plane Deformation Mechanics for Highly Stretchable Electronics. Adv. Mater. 2017, 29, 1604989. [CrossRef] [PubMed]

2. Li, C.-H.; Wang, C.; Keplinger, C.; Zuo, J.-L.; Jin, L.; Sun, Y.; Zheng, P.; Cao, Y.; Lissel, F.; Linder, C.; et al. A highly stretchable autonomous self-healing elastomer. Nat. Chem. 2016, 8, 618-624. [CrossRef] [PubMed]

3. Wu, X.; Ahmed, M.; Khan, Y.; Payne, M.E.; Zhu, J.; Lu, C.; Evans, J.W.; Arias, A.C. A potentiometric mechanotransduction mechanism for novel electronic skins. Sci. Adv. 2020, 6, eaba1062. [CrossRef] [PubMed]

4. Wang, S.; Xu, J.; Wang, W.; Wang, G.-J.N.; Rastak, R.; Molina-Lopez, F.; Chung, J.W.; Niu, S.; Feig, V.R.; Lopez, J.; et al. Skin electronics from scalable fabrication of an intrinsically stretchable transistor array. Nat. Cell Biol. 2018, 555, 83-88. [CrossRef]

5. Wang, J.; Cai, G.; Li, S.; Gao, D.; Xiong, J.; Lee, P.S. Printable Superelastic Conductors with Extreme Stretchability and Robust Cycling Endurance Enabled by Liquid-Metal Particles. Adv. Mater. 2018, 30, e1706157. [CrossRef]

6. Wang, J.-L.; Hassan, M.; Liu, J.-W.; Yu, S.-H. Nanowire Assemblies for Flexible Electronic Devices: Recent Advances and Perspectives. Adv. Mater. 2018, 30, e1803430. [CrossRef]

7. Sekitani, T.; Nakajima, H.; Maeda, H.; Fukushima, T.; Aida, T.; Hata, K.; Someya, T. Stretchable active-matrix organic light-emitting diode display using printable elastic conductors. Nat. Mater. 2009, 8, 494-499. [CrossRef]

8. Larson, C.; Peele, B.; Li, S.; Robinson, S.; Totaro, M.; Beccai, L.; Mazzolai, B.; Shepherd, R. Highly stretchable electroluminescent skin for optical signaling and tactile sensing. Science 2016, 351, 1071-1074. [CrossRef]

9. Liang, J.; Tong, K.; Pei, Q. A Water-Based Silver-Nanowire Screen-Print Ink for the Fabrication of Stretchable Conductors and Wearable Thin-Film Transistors. Adv. Mater. 2016, 28, 5986-5996. [CrossRef]

10. Yang, C.H.; Chen, B.; Zhou, J.; Chen, Y.M.; Suo, Z. Electroluminescence of Giant Stretchability. Adv. Mater. 2016, 28 , 4480-4484. [CrossRef]

11. Wang, J.; Yan, C.; Cai, G.; Cui, M.; Eh, A.L.-S.; Lee, P.S. Extremely Stretchable Electroluminescent Devices with Ionic Conductors. Adv. Mater. 2016, 28, 4490-4496. [CrossRef]

12. Someya, T.; Bao, Z.; Malliaras, G.G. The rise of plastic bioelectronics. Nature 2016, 540, 379-385. [CrossRef] 
13. Yokota, T.; Zalar, P.; Kaltenbrunner, M.; Jinno, H.; Matsuhisa, N.; Kitanosako, H.; Someya, T. Ultraflexible organic photonic skin. Sci. Adv. 2016, 2, e1501856. [CrossRef]

14. Chortos, A.; Liu, J.; Bao, J.L.Z. Pursuing prosthetic electronic skin. Nat. Mater. 2016, 15, 937-950. [CrossRef]

15. Chen, X.; Parida, K.; Wang, J.; Xiong, J.; Lin, M.-F.; Shao, J.; Lee, P.S. A Stretchable and Transparent Nanocomposite Nanogenerator for Self-Powered Physiological Monitoring. ACS Appl. Mater. Interfaces 2017, 9, 42200-42209. [CrossRef]

16. Zgierski-Johnston, C.; Ayub, S.; Fernández, M.; Rog-Zielinska, E.; Barz, F.; Paul, O.; Kohl, P.; Ruther, P. Cardiac pacing using transmural multi-LED probes in channelrhodopsin-expressing mouse hearts. Prog. Biophys. Mol. Biol. 2020, 154, 51-61. [CrossRef] [PubMed]

17. Zhou, Z.; Chen, K.; Li, X.; Zhang, S.; Wu, Y.; Zhou, Y.; Meng, K.; Sun, C.; He, Q.; Fan, W.; et al. Sign-to-speech translation using machine-learning-assisted stretchable sensor arrays. Nat. Electron. 2020, 3, 571-578. [CrossRef]

18. Huang, H.; Han, L.; Li, J.; Fu, X.; Wang, Y.; Yang, Z.; Xu, M. Super-stretchable, elastic and recoverable ionic conductive hydrogel for wireless wearable, stretchable sensor. J. Mater. Chem. A 2020, 8, 10291-10300. [CrossRef]

19. Hwang, B.-U.; Zabeeb, A.; Trung, T.Q.; Wen, L.; Lee, J.D.; Choi, Y.-I.; Lee, H.-B.; Kim, J.H.; Han, J.G.; Lee, N.-E. A transparent stretchable sensor for distinguishable detection of touch and pressure by capacitive and piezoresistive signal transduction. NPG Asia Mater. 2019, 11, 23. [CrossRef]

20. Huang, Y.; Hsiang, E.-L.; Deng, M.-Y.; Wu, S.-T. Mini-LED, Micro-LED and OLED displays: Present status and future perspectives. Light. Sci. Appl. 2020, 9, 1-16. [CrossRef]

21. Joo, W.-J.; Kyoung, J.; Esfandyarpour, M.; Lee, S.-H.; Koo, H.; Song, S.; Kwon, Y.-N.; Song, S.H.; Bae, J.C.; Jo, A.; et al. Metasurfacedriven OLED displays beyond 10,000 pixels per inch. Science 2020, 370, 459-463. [CrossRef]

22. Garnett, E.; Mai, L.; Yang, P. Introduction: 1D Nanomaterials/Nanowires. Chem. Rev. 2019, 119, 8955-8957. [CrossRef] [PubMed]

23. Dai, X.; Messanvi, A.; Zhang, H.; Durand, C.; Eymery, J.; Bougerol, C.; Julien, F.; Tchernycheva, M. Flexible Light-Emitting Diodes Based on Vertical Nitride Nanowires. Nano Lett. 2015, 15, 6958-6964. [CrossRef]

24. Guan, N.; Dai, X.; Messanvi, A.; Zhang, H.; Yan, J.; Gautier, E.; Bougerol, C.; Julien, F.; Durand, C.; Eymery, J.; et al. Flexible White Light Emitting Diodes Based on Nitride Nanowires and Nanophosphors. ACS Photon. 2016, 3, 597-603. [CrossRef]

25. Nadarajah, A.; Word, R.C.; Meiss, J.; Könenkamp, R. Flexible Inorganic Nanowire Light-Emitting Diode. Nano Lett. 2008, 8, 534-537. [CrossRef] [PubMed]

26. Kwon, O.E.; Shin, J.-W.; Oh, H.; Kang, C.-M.; Cho, H.; Kwon, B.-H.; Byun, C.-W.; Yang, J.-H.; Lee, K.M.; Han, J.-H.; et al. A prototype active-matrix OLED using graphene anode for flexible display application. J. Inf. Disp. 2019, 21, 49-56. [CrossRef]

27. Yin, D.; Feng, J.; Jiang, N.-R.; Ma, R.; Liu, Y.-F.; Sun, H.-B. Two-Dimensional Stretchable Organic Light-Emitting Devices with High Efficiency. ACS Appl. Mater. Interfaces 2016, 8, 31166-31171. [CrossRef]

28. Gilshteyn, E.P.; Romanov, S.A.; Kopylova, D.S.; Savostyanov, G.V.; Anisimov, A.S.; Glukhova, O.E.; Nasibulin, A.G. Mechanically Tunable Single-Walled Carbon Nanotube Films as a Universal Material for Transparent and Stretchable Electronics. ACS Appl. Mater. Interfaces 2019, 11, 27327-27334. [CrossRef] [PubMed]

29. Tuukkanen, S.; Hoikkanen, M.; Poikelispää, M.; Honkanen, M.; Vuorinen, T.; Kakkonen, M.; Vuorinen, J.; Lupo, D. Stretching of solution processed carbon nanotube and graphene nanocomposite films on rubber substrates. Synth. Met. 2014, 191, 28-35. [CrossRef]

30. Koester, R.; Hwang, J.-S.; Salomon, D.; Chen, X.; Bougerol, C.; Barnes, J.-P.; Dang, D.L.S.; Rigutti, L.; Bugallo, A.D.L.; Jacopin, G.; et al. M-Plane Core-Shell InGaN/GaN Multiple-Quantum-Wells on GaN Wires for Electroluminescent Devices. Nano Lett. 2011, 11, 4839-4845. [CrossRef]

31. Kapoor, A.; Guan, N.; Vallo, M.; Messanvi, A.; Mancini, L.; Gautier, E.; Bougerol, C.; Gayral, B.; Julien, F.H.; Vurpillot, F.; et al. Green Electroluminescence from Radial m-Plane InGaN Quantum Wells Grown on GaN Wire Sidewalls by Metal-Organic Vapor Phase Epitaxy. ACS Photon. 2018, 5, 4330-4337. [CrossRef]

32. Koester, R.; Hwang, J.S.; Durand, C.; Dang, D.L.S.; Eymery, J. Self-assembled growth of catalyst-free GaN wires by metal-organic vapour phase epitaxy. Nanotechnology 2009, 21, 015602. [CrossRef] [PubMed]

33. Tchoulfian, P.; Donatini, F.; Levy, F.; Amstatt, B.; Ferret, P.; Pernot, J. High conductivity in Si-doped GaN wires. Appl. Phys. Lett. 2013, 102, 122116. [CrossRef]

34. Tchoulfian, P.; Donatini, F.; Levy, F.; Dussaigne, A.; Ferret, P.; Pernot, J. Direct Imaging of p-n Junction in Core-Shell GaN Wires. Nano Lett. 2014, 14, 3491-3498. [CrossRef] [PubMed]

35. Eymery, J.; Salomon, D.; Chen, X.; Durand, C. Method of Selective Growth without Catalyst on a Semiconducting Structure. World Intellectual Property Organization Patent WO2,012,136,665, 11 October 2012.

36. Tessarek, C.; Heilmann, M.; Butzen, E.; Haab, A.; Hardtdegen, H.; Dieker, C.; Spiecker, E.; Christiansen, S. The Role of Si during the Growth of GaN Micro- and Nanorods. Cryst. Growth Des. 2014, 14, 1486-1492. [CrossRef]

37. Tsapenko, A.P.; Goldt, A.E.; Shulga, E.; Popov, Z.I.; Maslakov, K.I.; Anisimov, A.S.; Sorokin, P.B.; Nasibulin, A.G. Highly conductive and transparent films of HAuCl4-doped single-walled carbon nanotubes forflexible applications. Carbon 2018, 130, 448-457. [CrossRef]

38. Jacopin, G.; Bugallo, A.D.L.; Lavenus, P.; Rigutti, L.; Julien, F.H.; Zagonel, L.F.; Kociak, M.; Durand, C.; Salomon, D.; Chen, X.J.; et al. Single-Wire Light-Emitting Diodes Based on GaN Wires Containing Both Polar and Nonpolar InGaN/GaN Quantum Wells. Appl. Phys. Express 2011, 5, 014101. [CrossRef] 
39. Neplokh, V.; Messanvi, A.; Zhang, H.; Julien, F.; Babichev, A.; Eymery, J.; Durand, C.; Tchernycheva, M. Substrate-Free InGaN/GaN Nanowire Light-Emitting Diodes. Nanoscale Res. Lett. 2015, 10, 1-6. [CrossRef]

40. Messanvi, A.; Zhang, H.; Neplokh, V.; Julien, F.H.; Bayle, F.; Foldyna, M.; Tchernycheva, M. Investigation of photovoltaic properties of single core-shell InGaN/GaN wires. ACS Appl. Mater. Interfaces 2015, 7, 21898-21906. [CrossRef]

41. Neplokh, V.; Kochetkov, F.M.; Deriabin, K.V.; Fedorov, V.V.; Bolshakov, A.D.; Eliseev, I.E.; Islamova, R.M. Modified silicone rubber for fabrication and contacting of flexible suspended membranes of $\mathrm{n}-/ \mathrm{p}-\mathrm{GaP}$ nanowires with a single-walled carbon nanotube transparent contact. J. Mater. Chem. C 2020, 8, 3764-3772. [CrossRef]

42. Kochetkov, F.M.; Neplokh, V.V.; Deriabin, K.V.; Fedorov, V.V.; Bolshakov, A.D.; Eliseev, I.E.; Mikhailovskii, V.Y.; Ilatovskii, D.A.; Krasnikov, D.V.; Tchernycheva, M.; et al. Fabrication and electrical study of large area free-standing membrane with embedded GaP NWs for flexible devices. Nanotechnology 2020, 31, 46LT01. [CrossRef] [PubMed]

43. Nasibulin, A.G.; Ollikainen, A.; Anisimov, A.S.; Brown, D.P.; Pikhitsa, P.V.; Holopainen, S.; Penttilä, J.S.; Helistö, P.; Ruokolainen, J.; Choi, M.; et al. Integration of single-walled carbon nanotubes into polymer films by thermo-compression. Chem. Eng. J. 2008, 136, 409-413. [CrossRef]

44. Khabushev, E.M.; Krasnikov, D.V.; Zaremba, O.T.; Tsapenko, A.P.; Goldt, A.E.; Nasibulin, A.G. Machine Learning for Tailoring Optoelectronic Properties of Single-Walled Carbon Nanotube Films. J. Phys. Chem. Lett. 2019, 10, 6962-6966. [CrossRef]

45. Goldt, A.E.; Zaremba, O.T.; Bulavskiy, M.O.; Fedorov, F.S.; Larionov, K.V.; Tsapenko, A.P.; Popov, Z.I.; Sorokin, P.; Anisimov, A.S.; Inani, H.; et al. Highly efficient bilateral doping of single-walled carbon nanotubes. J. Mater. Chem. C 2021, 9, $4514-4521$. [CrossRef]

46. Kolaric, B.; Vandeparre, H.; Desprez, S.; Vallée, R.A.L.; Damman, P. In situ tuning the optical properties of a cavity by wrinkling. Appl. Phys. Lett. 2010, 96, 043119. [CrossRef]

47. Bai, J.; Cai, Y.; Feng, P.; Fletcher, P.; Zhao, X.; Zhu, C.; Wang, T. A Direct Epitaxial Approach to Achieving Ultrasmall and Ultrabright InGaN Micro Light-Emitting Diodes ( $\mu$ LEDs). ACS Photon. 2020, 7, 411-415. [CrossRef] [PubMed]

48. Konoplev, S.S.; Bulashevich, K.A.; Karpov, S.Y. From large-size to micro-LEDs: Scaling trends revealed by modeling. Phys. Status Solidi A 2018, 215, 1700508. [CrossRef]

49. Tchernycheva, M.; Messanvi, A.; Bugallo, A.D.L.; Jacopin, G.; Lavenus, P.; Rigutti, L.; Zhang, H.; Halioua, Y.; Julien, F.; Eymery, J.; et al. Integrated Photonic Platform Based on InGaN/GaN Nanowire Emitters and Detectors. Nano Lett. 2014, 14, 3515-3520. [CrossRef]

50. Sizov, V.S.; Neploh, V.V.; Tsatsulnikov, A.F.; Sakharov, A.V.; Lundin, W.V.; Zavarin, E.E.; Nikolaev, A.E.; Mintairov, A.M.; Merz, J.L. Study of tunneling transport of carriers in structures with an InGaN/GaN active region. Semiconductors 2010, 44, 1567-1575. [CrossRef]

51. Hong, Y.J.; Lee, C.H.; Yoon, A.; Kim, M.; Seong, H.K.; Chung, H.J.; Sone, C.; Park, Y.J.; Yi, G.C. Visible-Color-Tunable LightEmitting Diodes. Adv. Mater. 2011, 23, 3224. [CrossRef] 